\title{
A qualitative evaluation of a healthy cookery course in Ireland designed for adults with mild to moderate intellectual disability in Ireland
}

\author{
Annemarie E. Bennett ${ }^{1 *}$ and Cara Cunningham ${ }^{2}$ \\ ${ }^{1}$ School of Biological Sciences, Dublin Institute of Technology, Kevin Street, Dublin 8, Ireland \\ ${ }^{2}$ Community Nutrition and Dietetic Service, HSE Dublin Mid-Leinster, Ireland \\ * Corresponding author: abennet@tcd.ie
}

\begin{abstract}
Adults with an intellectual disability have poorer diets compared to the general adult population. The Able 2 Cook 4 Health cookery course aims to improve the diets of adults with mild to moderate intellectual disability. This study aims to evaluate the course by obtaining the views of course participants and the views of managers hosting the course. Thirty course participants took part in focus groups. Five managers hosting the course participated in a semi-structured interview. Positive features of the course included the group cooking, social interaction, and course instructors. Collaboration between centres hosting the course and participants' home environment is needed to help transfer the skills learned to all home settings. The Able 2 Cook 4 Health cookery course provided participants with an important social outlet in which to learn essential occupational skills. These findings could particularly influence the diets of adults with an intellectual disability moving into independent living.
\end{abstract}

\section{Keywords}

Adults, intellectual disability, healthy cooking, healthy diet

\section{Introduction}

Features of an intellectual disability include a reduced short-term memory and a reduced ability for abstraction, which increase the risk of making unhealthy choices in an already obesogenic environment (Elinder and Jansson, 2009; Schäfer Elinder et al., 2010). 
Individuals with an intellectual disability often have poor dietary habits (Draheim et al., 2007; Adolfsson et al., 2008), low physical activity levels (Emerson, 2005, McKeon et al., 2013), and weight disturbances (Hove, 2004; Bhaumik et al., 2008). As such, this group carry a greater chronic disease burden than the population in general (Reinders, 2002; Moran et al., 2005).

Positive day opportunities have been linked with improved self-esteem, wellbeing and independence (Knox and Hickson, 2001; Forrester-Jones et al., 2002). Social considerations such as friendships and recreational opportunities are important predictors of body mass index in those with an intellectual disability (Fujiura and Yamaki, 1997). Furthermore, the adverse mental and physical health consequences associated with poor social networks, loneliness, and social isolation are well documented (Stanfield, 1999; McVilly et al., 2006; Steptoe et al., 2013).

Since the late nineties, the number of individuals moving to assisted independent living in Ireland has increased, to promote greater independence and responsibility amongst this group (McNally, 2006). However, the resulting less restrictive living environments (Doody and Doody, 2012) can result in greater access to unhealthy food and less emphasis on physical activity (Draheim, 2007; Johnson, 2009).

The Able 2 Cook 4 Health cookery course is a nutrition education course designed by dietitians for adults with mild to moderate intellectual disabilities. It is particularly useful for individuals moving to assisted independent living. The 6-session course provides evidence-based dietary advice in a sociable environment. Each session lasts 2.5 hours and involves: group cooking; activities and games to reinforce health messages; and a sit-down meal (Table 1). The Able 2 Cook 4 Health cookery courses are delivered by suitable lay members of the community. Lay individuals express an interest in delivering the 
course, and if they are deemed suitable by the course co-ordinator, they take part in one day of training to become course instructors.

\section{[TABLE 1]}

The Mid-Leinster Nutrition and Dietetic Service advertise the course to health centres that care for adults with intellectual disabilities. Health centres interested in the course contact the Service to arrange course delivery.

The cookery course aims to help participants to make healthier dietary decisions by translating key health messages into practice through simple cookery lessons. The aim of this study was to evaluate the Able 2 Cook 4 Health cookery course by determining the views of course participants and the views of managers who host the course in their centre. Views on the delivery and content of the course were sought, in addition to views on improvements that could be made to the course.

\section{Method}

\section{Sample selection}

Ethical approval for the study was obtained from the Irish Council for Bioethics. The study was conducted in accordance with the ethical principles of the Declaration of Helsinki (World Medical Association, 2013).

When conducting focus groups with adults with intellectual disability, it is generally accepted that three to five focus groups are sufficient to gain the diversity of views needed to achieve saturation (Bloor et al., 2001). As such, five Able 2 Cook 4 Health cookery courses which had finished no more than two weeks previously, were used to recruit participants to focus groups.

For each cookery course, the manager of the centre hosting the course was also interviewed to determine their views on the implementation and outcomes of the course. 
Obtaining the views of the course participants

A semi-structured focus group interview schedule was developed (Table 2). Everyday words were used. This interview schedule was piloted with one group to ensure the language and visual aids used were acceptable to the intellectual capacities likely to be encountered in the study.

\section{[TABLE 2]}

For two topics, (Topics 2 and 3; Table 2), participants were asked an open-ended question on the topic, followed by a set of possible responses which were pictorially represented. Each participant was asked to rank or comment on these possible responses. This approach allowed participants to offer their own views first, but it also obtained feedback on multiple aspects of the course and ensured that all participants had the opportunity to provide feedback.

Each focus group took place in the centre where the Able 2 Cook 4 Health cookery course had been held. The facilitator attended each centre 30 minutes prior to the designated time for the focus group. During this time, the support person assigned to sit with the focus group was sought out to clarify their role. The role of the support person was to support a participant, where necessary, to partake in the focus group; a support person was not to speak for, or on behalf of, a participant (Llewellyn and Northway, 2008). As such, there were no significant issues with support persons speaking on behalf of participants throughout the focus groups.

A user-friendly information sheet and clear verbal explanation conveyed the nature and purpose of the focus group to course participants. Written informed consent was obtained from participants once the residential manager confirmed that participants had the capacity to give such consent. Where written consent was not possible, the support person provided 
consent on their behalf. Details on the living situation and age of each participant were obtained once consent was provided. All focus groups were audio-taped.

To maintain the interest of participants, each focus group lasted no longer than 45 minutes. To facilitate the focus group, ground rules were established at the outset. Participants agreed (1) to speak one at a time and (2) to respect everyone else's opinion. These rules were observed by participants throughout discussions.

A personalised 'thank you' card was given to each focus group participant to recognise the value of their time and opinions.

\section{Obtaining the views of managers hosting the course}

An interview schedule for centre managers was developed. The schedule covered three main areas: (1) suitability of course delivery and layout; (2) suggested changes to the course; and (3) perceived benefits of the course for participants. Each interview took place after the focus group in the centre where the cookery course had been held. A user-friendly information sheet described the nature and purpose of the study. Written informed consent was obtained from managers. All interviews were audio-taped.

\section{Data analysis}

Tapes from the focus group discussions and the qualitative interviews were transcribed verbatim. Content analysis was used to analyse the data (Sandelowski, 2000). The aim of content analysis is to present a substantial description of what participants said, as opposed to drawing deep implications from the data. The four-stage Constant Comparative Method (Lincoln and Guba, 1985) was used to manage the data collected.

First, once the researcher was familiar with the transcripts, the data was loosely grouped into suitable categories. Then, a more in-depth analysis ensured that data was assigned to the most appropriate category, with new categories developed as needed. Each 
transcript was reviewed in its entirety to ensure that all relevant quotes had been coded. All categories were then revised and refined; some categories with similar quotes were collapsed and given a more appropriate title. Final categories were decided upon, and a brief description was applied to each category. Consultation took place between the two authors on the final interpretations.

The development of categories was an ongoing and iterative process. Changes were made upon review of the data and upon consultation with the second researcher. Only one researcher was responsible for collecting and transcribing the data, and this helped ensure a consistent approach to analysis and interpretation.

\section{Results}

\section{Characteristics of course participants}

Thirty participants $(40 \%(n 12)$ male, $60 \%(n 18)$ female; $100 \%(n 30)$ Irish nationality) from five separate cookery courses took part in focus groups to provide feedback. Focus groups ranged in size from four to nine participants. The small size of the focus groups ensured that everyone had the opportunity to express themselves.

Two participants in one centre could not provide written consent; this was provided by the manager of the centre on their behalf. The same two participants could not verbalise their views; an interpreter proficient in the use of the manual sign system "Lámh" (designed for individuals with intellectual disabilities and communication needs) communicated on their behalf.

Participants ranged in age from nineteen years to fifty-three years. Of the thirty participants, seven (23\%) were living in assisted independent community housing, fifteen (50\%) were living in their family home, and eight (27\%) were living in supervised residential facilities. 
Results of focus group discussions with course participants

Main reasons for doing the course

Participants' main reasons for doing the course were grouped into three categories, as highlighted in Table 3. Participants repeatedly noted the importance of the course for improving and maintaining good health. Another common reason given for taking part was to enhance practical living skills, with a view to increased independence. Using the skills learned during the course to contribute to their family household was emphasized by several participants; they wanted to increase their skill-set to cook not only for themselves, but also for their families.

\section{[TABLE 3]}

\section{Most enjoyable aspects of the course}

When asked the open-ended question on the most enjoyable aspects of the course, the opportunities to be sociable were most remarked upon by the participants.

"I never got to spend much time with my friends before...I was always separate because I would be with my family."

"It was a nice time...working together and spending time together and working as a group."

Other enjoyable sociable aspects of the course were noted by participants, including "eating what we had made after cooking together" and "cleaning up after." Enjoying the time being taught by the course instructor was also noted under the open-ended question.

"She was lovely... a good friend."

"I liked doing everything with her; I'm terrible fond of her."

Similarly, when presented with the pre-determined set of possible responses on the most enjoyable aspects of the course, cooking together (n20), eating together (n5) and the course teacher were chosen $(n 5)$. 
Suggested changes to the course

The participants' suggested changes to the course were classed into three key areas, as highlighted in Table 4. Although probed, some participants felt that no changes were needed to the course, "No, no, I want it [the course] to stay the same."

\section{[TABLE 4]}

When asked about the number, length, and format of classes, the vast majority of participants wanted more cookery classes, though not longer classes. All participants stated that they would like to cook different dishes if they had the opportunity to do the course again. The majority of participants preferred working as a group to produce a single dish. A number of participants from one course stated that they would prefer to cook individually. This was the largest group to complete the cookery course, with nine participants.

\section{Main health messages learned}

The recall of the healthy eating games played varied, ranging from no recall to participants recalling and elaborating on health messages.

"Well, we learned about salt. You see, sometimes it depends on what you put into the food, but then some foods are already salty...like processed foods."

"I've cut down on the sweets and I don't put too much butter on brown bread - I put some, but not a lot - and then some salad, I try to eat salad."

Healthy eating messages were also expressed intermittently throughout the focus group discussion.

"Breakfast is important...yeah, you need to be having your breakfast every day."

“Crispbread would be good for you, you know. It's not fattening, it's the butter that would be fattening...it's what you put on it that matters!"

"You're better off drinking water and trying to cut down on the fizzy drinks." 


\section{Characteristics of managers hosting the course}

The manager in each of the five centres hosting the cookery course consented to take part in an interview. All managers had been present during the cookery classes. All managers interviewed were female, had caring responsibilities in their centre, and had at least 6 years experience working in the area of intellectual disability.

Results of interview with managers

Assessment of course instructors

All managers acknowledged that all participants were meaningfully included in the cooking process.

"Everybody in the group - regardless of ability - got a job to do and participated."

Very importantly, managers also stated that the course instructors were able to draw out skills in the participants that the managers were not aware of.

We saw skills that we wouldn't have thought were there in some of the guys. You know, when you have somebody independent come in who doesn't know anything about them, they were able to take off and just do whatever they were able to do."

This observation is particularly important, given that it may improve the attitudes and expectations of the course managers towards participants.

Suitability of the theoretical content

The theoretical content of the course was largely praised by managers, who emphasized the importance of using visual aids to assist teaching during the course.

"These people might be verbally impaired (...), but they will be able to point at a picture and tell you that they do or don't understand."

"I thought that some of the theory - like the food pyramid - might be a little difficult for some to understand, but then, some did understand that I thought would not have." 
Alongside praising the theoretical content of the course, it is noteworthy that some managers underestimated the ability of participants to understand the theory. Just as some managers underestimated the practical skills of participants, the intellectual ability of participants was also underestimated in some cases.

Suitability of the cookery content

The dishes cooked were deemed largely suitable for the skill-set of the participants.

"I think it was very suitable...very much so. It was at their level and they were happy to participate and engage in the activity."

The importance of being able to duplicate the cooking process was highlighted by all managers.

"All the equipment you need for the dishes that are made is found in a normal domestic kitchen - that's crucial."

In addition to the course instructors providing a platform for participants to exhibit their skill, the extent of their skills became apparent through the cooking process. One manager stated that cooking with the participants gave her a better understanding of their different abilities.

"It taught us a lot about what they are able to do."

Participant involvement in food production in one centre was being reviewed by one manager as a result of cooking with participants.

"This gave us ideas about how we can change and handle meal planning with them and training about food management."

Implementation of the course

Providing assistance to the centre to reinforce the messages of the course was highlighted as a potential improvement. 
"Maybe we could get a photocopy of what is done with them in class so that we could do it again during the week...that way we would always be linking back to what they are learning”.

Working to ensure that the skills learned could be transferred to the participants' living environment outside the centre was also emphasized. The opportunities to prepare meals are limited or non-existent for participants living in supervised residential facilities. Managers emphasized the importance of seeing such practices change.

"We need to reach them [staff in residential facilities] so that the clients could be allowed to prepare their own lunch. Otherwise it's futile - we're doing it here and they are just going home getting everything handed to them."

Managers also felt that completing the course should be more formally recognised, perhaps by providing a certificate and an appropriate cookery book or appropriate cooking materials to participants.

"I think there needs to be something a little more made of it. It's an achievement and they love getting their certificates, but (...) if there was something user-friendly that they could take home with them, (...) they could cook at home and say that they did a cookery programme and automatically confidence is going to build up."

Perceived benefits of the course to participants

Managers felt that increased independence amongst participants was one of the most valuable aspects of the course.

"Since they are going to be living independently, they will have less support from us. So for them to understand the concept of three main meals and learning to cook simple dishes is great." 
"Mammies and daddies do an awful lot for them, and they are mollycoddled a bit, you know? But since this programme has started, the parents have found that they are more willing to get up and just do things."

The sociable aspect of the course was emphasized as important, since it was seen to help participants to converse more and to learn more about co-operation.

The contribution of the course to meeting some of the basic needs of the participants was also emphasized as a benefit of the course.

"Every client should have access to ordinary and basic cooking skills - but they don't. And it's such a basic need to be able to provide for yourself in that way."

\section{Discussion}

The Able 2 Cook 4 Health cookery course was reported to provide participants with a social outlet in which important health messages were communicated in an accessible manner.

Translating key nutritional concepts into practical tasks was fundamental to the successful delivery of the course. Individuals with an intellectual disability have a reduced understanding of abstract concepts (Hobson and Lee, 1989). As such, participants actively participated in cooking healthy meals and played interactive games on common food issues. This practical approach was rooted in the activities of everyday life; it sought to enable participants to easily transplant the skills learned during the course into their everyday routine.

Course participants also demonstrated an understanding of simple nutrition messages to guide their eating habits. For example, participants noted the difference between inherently salty foods and the discretionary use of salt, and recognised the undesirable addition of fats to otherwise low-fat foods. This knowledge, if translated into long-term dietary habits, could contribute to improved health outcomes (World Health Organisation, 2004; World Health Organisation, 2011). 
To ensure that the skills and knowledge acquired during the course are used upon course completion, the living environment of participants must be considered (Baranowski et al., 2003; Doody and Doody, 2012; Spanos et al., 2013). Managers acknowledged that the dishes prepared required equipment found in a standard domestic kitchen. This should help participants to implement their newly acquired skills, particularly participants living in assisted independent housing or in the family home. However, participants in supervised residential housing did not have the opportunity to cook or shop for themselves. As such, steps are needed to make supervisors in such housing aware of the importance of enabling participants to take more responsibility for their meals. Collaboration with each participant's home environment is also needed to ensure that the skills and knowledge acquired during the course are sustained to support a healthier diet.

Collaboration with the home environment is also important for participants' selfesteem. Participants used the course to become more independent and to increase their contribution to their family home. In a society which values achievement, competency and productivity (Markwick and Sage, 1997), this desire to contribute in a measurable way to a household is expected. One manager observed that course participants were "mollycoddled" to some extent by their families, who possibly underestimate the skill-set of the participants. As such, family members and carers must be made aware of the importance of including participants in meaningful household activities. Doing so can ensure that participants use their newly acquired skills and knowledge at home, and thus make their desired contribution to their household.

A particularly noteworthy finding was the surprise expressed by some managers at the skills exhibited by some participants throughout the course. People with intellectual disabilities are often disabled in their own emotional and intellectual creativity due to the low expectations of those around them (Seligman and Darling, 2007; Doody and Doody, 2012). 
Actively taking part in the classes with participants seemed to help managers overcome some of their assumptions regarding the participants' abilities. To help broaden the understanding of mangers about the abilities of course participants, it may be advisable to state that managers must participate in a minimum number of sessions in future courses.

The importance of meaningful social interaction was recognised in the design of the course. Cooking as a group provided an additional social network for each course participant. Unsurprisingly, the opportunities to be sociable were highlighted as one of the most valuable aspects of the course. The resulting social network included individuals with and without intellectual disabilities. This type of social network is an effective one for meeting the social and emotional needs of this population (McVilly et al., 2006).

The course instructors positively contributed to each participant's social network. Training lay members of the community to deliver the course helps ensure that the course instructors are genuinely interested in helping this population group to learn new skills. This helps to create a safe learning environment where mistakes can be made without embarrassment (Markwick and Sage, 1997).

Both managers and course participants stated that the completion of the course should be marked more formally. Formally recognising the progress made and skills acquired can effectively boost confidence and enhance self-image (Markwick and Sage, 1997). As suggested, the provision of materials, such as an adapted cookery book, might help participants to not only sustain their new skills and knowledge, but also remind them of a positive experience.

Before drawing final conclusions on the findings of this study, the methodological limitations must be considered. Due to the qualitative study design, the results cannot be used quantitatively and findings cannot be generalised. The study was conducted within a fortnight of participants completing the course, so no views on long-term outcomes were recorded; this 
is a consideration for future courses. However, it is positive that even with the time lapse of a fortnight, many participants were able to reflect, in detail, on the course. The quality of the data obtained heavily relies on the skills of the facilitator. However, the facilitator of the focus groups and interviews did have experience with qualitative data collection and analysis. In analysis, the use of the Constant Comparative Method helped to ensure the rigour of methods and trustworthiness of the results presented.

Individuals with intellectual disability are the most valid source of information about their lives (McCarthy, 1998). Focus groups allow for a greater number of opinions and suggestions, deeper exploration of topics, and do not require participants to possess written language skills (O’Day and Killeen, 2002). Qualitative research enables researchers to empathise with respondents and discover how they see the reality of a particular situation (Krueger, 2009), which was the aim of this study.

Many people with an intellectual disability do not consume a balanced diet and experience consistent nutritional impairment (Hamilton et al., 2007). A complex repertoire of occupational skills is required to live independently (Cardol et al., 2012), and safe food preparation and healthy cooking are part of this set of essential skills. Learning such skills in an environment of positive regard helps to enhance participants' self-efficacy and confidence. From the observations made in this study, the Able 2 Cook 4 Health cookery course met most expectations; it enabled participants to develop practical and healthy life skills in a supportive environment. 


\section{Funding acknowledgement}

This work was supported by Westmeath Community Development

\section{Conflict of interest}

No conflict of interest to declare 


\section{References}

Adolfsson P, Mattsson Sydner Y, Fjellström C, Lewin B and Andersson A (2008) Observed dietary intake in adults with intellectual disability living in the community. Food and Nutrition Research 52, published online.

Baranowski T, Cullen KW, Nicklas T, Thompson D and Baranowski J (2003) Are current health behavioral change models helpful in guiding prevention of weight gain efforts? Obesity Research 11 (10): 23S-43S.

Bhaumik S, Watson JM, Thorp CF, Tyrer F and McGrother CW (2008) Body mass index in adults with intellectual disability: Distribution, associations and service implications - a population-based prevalence study. Journal of Intellectual Disability Research 52 (4): 287-298.

Bloor M, Frankland J, Thomas M and Robson K (2001) Composition of groups. In: Focus groups in social research: Introducing qualitative methods. London: Sage Publications, pp. 19-36.

Cardol M, Rijken M and van Schrojenstein Lantman-de Valk H (2012) People with mild to moderate intellectual disability talking about their diabetes and how they manage. Journal of Intellectual Disability Research 56 (4): 351-360.

Doody CM and Doody O (2012) Health promotion for people with intellectual disability and obesity. British Journal of Nursing 21 (8): 460-465.

Draheim CC (2007) Cardiovascular disease prevalence and risk factors of persons with mental retardation. Mental Retardation and Developmental Disabilities Research Reviews $12(1): 3-12$.

Elinder LS and Jansson M (2009) Obesogenic environments - Aspects on measurement and indicators. Public Health Nutrition 12 (3): 307-315. 
Emerson E (2005) Underweight, obesity and exercise among adults with intellectual disabilities in supported accommodation in Northern England. Journal of Intellectual Disability Research 49 (2): 134-143.

Forrester-Jones R, Carpenter J, Cambridge P, Tate A, Hallam A, Knapp M et al. (2002) The quality of life of people 12 years after resettlement from long-stay hospitals: Users' views on their living environment, daily activities and future aspirations. Disability and Society 17 (7): 741-758.

Fujiura GT and Yamaki K (1997) Analysis of ethnic variations in developmental disability prevalence and household economic status. Mental Retardation 35 (4): 286-94.

Hamilton S, Hankey CR, Miller S, Boyle S and Melville CA (2007) A review of weight loss interventions for adults with intellectual disabilities. Obesity Reviews 8 (4): 339-345.

Hobson RP and Lee A (1989) Emotion-related and abstract concepts in autistic people: Evidence from the British Picture Vocabulary Scale. Journal of Autism and Developmental Disorders 19 (4): 601-623.

Hove O (2004) Weight survey on adult persons with mental retardation living in the community. Research in Developmental Disabilities 25 (1), 9-17.

Johnson CC (2009) The benefits of physical activity for youth with developmental disabilities: A systematic review. American Journal of Health Promotion 23 (3): 157-167.

Knox M and Hickson F (2001) The meanings of close friendships: the views of four people with intellectual disabilities. Journal of Applied Research in Intellectual Disabilities 14 (3): 276-291.

Krueger RA (1994) Focus Groups: A practical guide for applied research. Thousand Oaks, CA: Sage Publications.

Kreuger RA (2009) Overview of focus groups. In: Focus Groups: A practical guide for applied research. California: Sage Publications, pp. 2-15. 
Llewellyn P and Northway R (2008) The views and experiences of people with intellectual disabilities concerning advocacy: a focus group study. Journal of Intellectual Disabilities 12 (3): 213-228.

Lincoln YS and Guba EG (1985) Naturalistic inquiry. California: Sage Publications.

Markwick A and Sage J (1997) Self-image and people with learning difficulties. British Journal of Nursing 6 (2): 99-102.

McCarthy M (1998) Whose body is it anyway? Pressures and control for women with learning disabilities. Disability and Society 13 (4): 557-574.

McKeon M, Slevin E, Taggart L. (2013) A pilot survey of physical activity in men with an intellectual disability. Journal of Intellectual Disabilities 17 (2): 157-167.

McNally S (2006) Person-centred planning in intellectual disability nursing. In: Care Planning and Delivery in Intellectual Disability Nursing. Oxford: Blackwell Publishing, pp. 68-84.

McVilly KR. Stancliffe RJ, Parmenter TR and Burton-Smith RM (2006) 'I get by with a little help from my friends': Adults with intellectual disability discuss loneliness. Journal of Applied Research in Intellectual Disabilities 19 (2): 191-203.

Moran R, Drane W, McDermott S, Dasari S, Scurry JB and Platt T (2005) Obesity among people with and without mental retardation across adulthood. Obesity Research 13 (2): 342-349.

O'Day B. and Killeen M (2002) Research on the lives of persons with disabilities: The emerging importance of qualitative research methodologies. Journal of Disability Policy Studies 13 (1): 9-15.

Reinders J (2002) The good life for citizens with intellectual disability. Journal of Intellectual Disability Research 46 (1): 1-5. 
Robertson J, Emerson E, Gregory N, Hatto C, Turner S, Kessissoglou S and Hallam A (2000) Lifestyle related risk factors for poor health in residential settings for people with intellectual disabilities. Research in Developmental Disabilities 21 (6): 469-486.

Sandelowski M (2000) Focus on research methods. Whatever happened to qualitative description? Research in Nursing and Health 23 (4) 334-340.

Schäfer Elinder L, Bergström H, Hagberg, J, Wihlman U and Hagströmer M (2010) Promoting a healthy diet and physical activity in adults with intellectual disabilities living in community residences: Design and evaluation of a cluster-randomized intervention. BMC Public Health 10, 761-767, published online.

Seligman M and Darling RB (2007) Approaches to intervention. In: Ordinary Families, Special Children. New York: The Guilford Press, pp. 279-381.

Spanos D, Hankey CR, Boyle S, Koshy P, Macmillan S, Matthews L, et al. (2013) Carers' perspectives of a weight loss intervention for adults with intellectual disabilities and obesity: a qualitative study. Journal of Intellectual Disability Research 57 (1): 90-102.

Stanfield S (1999) Social support and social cohesion. In: Social Determinants of Health. Oxford: Oxford University Press, pp. 155-178.

Steptoe A, Shankar A, Demakakos P, and Wardle J (2013) Social isolation, loneliness, and all-cause mortality in older men and women. Proceedings of the National Academy of Sciences of the United States of America 110 (15): 5797-5801.

Stewart DW, Shamdasini PN and Rook DW (2007) Analyzing focus group data. In: Focus groups: Theory and Practice. California: Sage Publications, pp. 109-134.

World Health Organisation (2004) Global strategy on diet, physical activity and health. WHO Press, Switzerland.

World Health Organisation (2011) Strategies to monitor and evaluate population sodium consumption and sources of sodium in the diet. WHO Press, Switzerland. 
World Medical Association (2013) Declaration of Helsinki - Ethical principles for medical research involving human subjects. Available at: http://www.wma.net/en/30publications/10policies/b3/ [Accessed 04 January 2014]. 
Table 1: Core topics and main messages of the 6-week Able 2 Cook 4 Health cookery course designed for adults with mild to moderate intellectual disabilities

\begin{tabular}{lll}
\hline Week & Class title & Main messages taught \\
Week 1 & A healthy balanced diet & $\begin{array}{l}\text { (1) Everyone should eat breakfast (2) Choose more food from } \\
\text { the bottom shelves of the food pyramid (3) Keep foods from } \\
\text { the top shelf of the food pyramid for special occasions }\end{array}$ \\
Week 2 & Lower fats, but still tasty & $\begin{array}{l}\text { (1) Fats are high in calories (2) Too much fat makes us gain } \\
\text { weight (3) We need to eat less foods that are high in fat }\end{array}$ \\
Week 3 & Making healthier choices & $\begin{array}{l}\text { (1) Good food choices are healthy food choices (2) How to } \\
\text { make healthy food choices }\end{array}$ \\
Week 4 & Fruits and Vegetables & $\begin{array}{l}\text { (1) Fruits and vegetables are low in fat and high in fibre, } \\
\text { vitamins and minerals (2) Fruits and vegetables make a healthy } \\
\text { snack }\end{array}$ \\
Week 5 & Quick tasty healthy snacks & $\begin{array}{l}\text { (1) Snack foods can be high in fat and calories (2) It's just as } \\
\text { easy to make a tasty healthy snack as it is to buy a snack }\end{array}$ \\
Week 6 & Finishing up and revision & (1) Revision of main health messages
\end{tabular}


Table 2: Semi-structured interview schedule developed to determine course participants' views on the Able 2 Cook 4 Health cookery course

\section{Topic 1 - Main reasons for doing the course}

Why did you choose to do the Able to Cook 4 Health course?

\section{Topic 2 - Most enjoyable aspects of the course}

Open question asked first: What did you like the most about the course?

Closed question asked to obtain data on several aspects: Can you rank these aspects of the course (pictorially represented), from most enjoyable to least enjoyable? (1) Cooking (2) Eating together (3) Spending time working with a group (4) Games played (5) Course teacher

\section{Topic 3 - Preferred changes to the course}

Open question asked first: If you do the course again, what would you like to be different about it? Closed question asked to obtain data on a variety of possible changes: Can you rank these possible changes to the course (pictorially represented), from the change you most want, to the change you least want? (1) More classes (2) Longer classes (3) Prepare different dishes (4) Cook alone

Topic 4 - Main health messages learned

You played different games about healthy eating during the course. Can anyone describe any of these? 
Table 3: The main reasons given by course participants for doing the Able 2 Cook 4 Health cookery course

\begin{tabular}{ll}
$\begin{array}{l}\text { Reasons for wanting to do the } \\
\text { course }\end{array}$ & Typical quote \\
\hline $\begin{array}{l}\text { Improve or maintain health } \\
\text { (n15) }\end{array}$ & $\begin{array}{l}\text { "I volunteered to do it to eat healthy and keep healthy and, you } \\
\text { know, for your health - your healthy options." }\end{array}$ \\
\hline $\begin{array}{l}\text { Increased independence } \\
\text { (n11) }\end{array}$ & $\begin{array}{l}\text { You know - to be able to cook my own meals and that, rather than } \\
\text { depending on my mother or somebody else to get them for me." }\end{array}$ \\
$\begin{array}{l}\text { Greater contribution to the } \\
\text { family household }(n 7)\end{array}$ & $\begin{array}{l}\text { "Say if you have a big family of ten people at home, you can take the } \\
\text { pressure off your mother doing the cooking the whole time." }\end{array}$ \\
\hline
\end{tabular}


Table 4: Course participants' suggested changes to the Able 2 Cook 4 Health cookery course

\begin{tabular}{|c|c|}
\hline Suggested area of change & Relevant quote \\
\hline $\begin{array}{l}\text { Additions to the existing } \\
\text { course content }(n 8)\end{array}$ & $\begin{array}{l}\text { "Maybe to go through the cost of everything...how to look for good value } \\
\text { when you shop." } \\
\text { "If we did it again, I would like different cooks...emm, not the same foods } \\
\text { we made before." }\end{array}$ \\
\hline $\begin{array}{l}\text { Changes to the course } \\
\text { layout }(n 8)\end{array}$ & "I'd like more classes. I love it - I love doing it." \\
\hline $\begin{array}{l}\text { Receive a hard-copy of } \\
\text { the course content }(n 6)\end{array}$ & $\begin{array}{l}\text { "My Mam said that if I had the recipes, she would show me if I got stuck } \\
\text { along the way." } \\
\text { "It might be nice to have a small book about reading the labels and all } \\
\text { that...like looking at the price and that." } \\
\text { "Knowing what to do if you cut yourself." }\end{array}$ \\
\hline
\end{tabular}

